\title{
GIS-based bivariate statistical techniques for groundwater potential analysis (an example of Iran)
}

\author{
Ali Haghizadeh ${ }^{1}$, Davoud Davoudi Moghaddam ${ }^{1}$ and Hamid Reza Pourghasemi ${ }^{2} *$ \\ ${ }^{1}$ Department of Range and Watershed Management Engineering, Lorestan University, Lorestan, Iran. \\ ${ }^{2}$ Department of Natural Resources and Environmental Engineering, College of Agriculture, Shiraz University, \\ Shiraz, Iran. \\ *Corresponding author.e-mail: hr.pourghasemi@shirazu.ac.ir; hamidreza.pourghasemi@yahoo.com
}

MS received 8 September 2016; revised 21 May 2017; accepted 25 May 2017; published online 23 November 2017

Groundwater potential analysis prepares better comprehension of hydrological settings of different regions. This study shows the potency of two GIS-based data driven bivariate techniques namely statistical index (SI) and Dempster-Shafer theory (DST) to analyze groundwater potential in Broujerd region of Iran. The research was done using 11 groundwater conditioning factors and 496 spring positions. Based on the ground water potential maps (GPMs) of SI and DST methods, $24.22 \%$ and $23.74 \%$ of the study area is covered by poor zone of groundwater potential, and $43.93 \%$ and $36.3 \%$ of Broujerd region is covered by good and very good potential zones, respectively. The validation of outcomes displayed that area under the curve (AUC) of SI and DST techniques are $81.23 \%$ and $79.41 \%$, respectively, which shows SI method has slightly a better performance than the DST technique. Therefore, SI and DST methods are advantageous to analyze groundwater capacity and scrutinize the complicated relation between groundwater occurrence and groundwater conditioning factors, which permits investigation of both systemic and stochastic uncertainty. Finally, it can be realized that these techniques are very beneficial for groundwater potential analyzing and can be practical for water-resource management experts.

Keywords. Groundwater; statistical index; Dempster-Shafer theory; water resource management; GIS.

\section{Introduction}

Water scarcity exists all around the world and it has quickly increased requirements for freshwater (Todd and Mays 2005; Manap et al. 2012). Due to the fact that there are a lot of desert lands without green pastures and forests in Iran, this country is heading towards a lot of water problems (Bastani et al. 2010). In waterless provinces and territories of Iran, groundwater reservoirs are supposed to be the principal source of water supply. Unfortunately, as a result of high extraction rates of water and unsuitable management plans, the groundwater levels have been falling in the last few decades (Nosrati and Eeckhaut 2012). So, groundwater potential analyzing is vital to administer groundwater reservoirs, especially in data-scarce regions (Mondal et al. 2008; Rahmati et al. 2014).

Generally, the prevalent methods for detection of groundwater resources have some weaknesses, like complexity, uneconomical, time consuming, very expensive, and sometimes unsuccessful (Jha et al. 2010). 
In the view of these weaknesses, there is a strong requirement for reassessment of groundwater resources using pioneer technology such as Geographic Information System (GIS), Global Positioning System (GPS), and Remote Sensing (RS) (Srivastava et al. 2013; Singh et al. 2014). The growth of these tools has also prepared another time and cost impressive means of groundwater potential analysis (Nampak et al. 2014; Masoud and El Osta 2016). So, according to Davoodi Moghaddam et al. (2015), groundwater potential analysis can be very useful and helpful for managers to prepare best management scenarios of water resources in any region.

In recent years, various researchers have strived to describe productivity of groundwater applying many data-driven and knowledge-driven models (Corsini et al. 2009; Ozdemir 2011a, b; Agarwal et al. 2013; Park et al. 2014; Shahid et al. 2014; Al-Abadi 2015; Naghibi et al. 2015; Pourtaghi and Pourghasemi 2015; Mahesvaran et al. 2016; Mogaji et al. 2016). According to Solomatine et al. (2008), data-driven models (DDM) consider and analyze relationship between variables of a system such as inputs, internal and outputs without giving attention to the behaviour of physical systems. So, these models are known as computational intelligence and machine learning techniques to use for replacing physically based models. In contrast, knowledge-driven methods (KDM) use rich prior knowledge for model building based on knowledge engineering and management technologies (Azkune et al. 2015). Azkune et al. (2015) stated that the mentioned models (KDM) are based on real world observation; so, one of the most important advantages is the use of generic knowledge rather than data.

The current investigation paper describes the usage of two GIS-based data-driven SI and DST techniques to analyze groundwater capacity using spring locations as groundwater indicator in the Broujerd region, Lorestan Province, Iran. Sufficient and persistent resources of high quality water from ground reservoirs are vital for sustained domestic, agricultural and industrial use throughout Broujerd region. Mapping of groundwater potential prepare better comprehension of the hydrological conditions of the region and can be applied in waterless regions. This is a promising approach for impressive management and planning of important groundwater resources, especially in datascarce developing regions. In addition, the usage of GIS-based SI technique in groundwater potential analyzing (using spring locations) is used for the first time in this study, because of in above several literature reviews were used for landslide susceptibility and also, the application of DST technique is very new in groundwater potential analysis.

\section{Study area}

The Broujerd region covers an area of nearly $1676 \mathrm{~km}^{2}$ and is located in Broujerd region of Lorestan Province, Iran, latitudes $33^{\circ} 35^{\prime}-34^{\circ} 10^{\prime} \mathrm{N}$ and longitudes $48^{\circ} 20^{\prime}-49^{\circ} 10^{\prime} \mathrm{E}$ (figure 1 ). The topographical altitude of the Broujerd region varies from 1466 to $3621 \mathrm{mamsl}$, with an average of $2543 \mathrm{~m}$. The region receives an average annual rainfall of $\sim 458 \mathrm{~mm}$. Depending on recorded meteorological data in Broujerd Station for the duration (1989-2015), the monthly average, minimum, and maximum temperatures are $14.7,8.2$, and $21.3^{\circ} \mathrm{C}$, respectively (Iranian Meteorological Organization 2015). The Broujerd region, made up of five landuse patterns namely agriculture, orchard, forest, rangeland, and settlement areas. The major land use is rangeland type and covers almost $42 \%$ of Broujerd region. Depending on geological survey of Iran (GSI 1997), the lithology of study area consisted of the units represented as $\mathrm{Qt}_{2}$ (pediment fan and valley terrace deposits; $49 \%$ of study area), KPAiai (granite to diorite intrusive rocks), Phh (phyllite, slate, and meta-sandstone), JKbs (limestone), Mf (reefal coral and algal limestone), MJst (meta-limestone, meta-quartzarenite, phyllite, and meta-volcanics), and h (hornfels, andalusite, and carbonate rocks), which are appropriate lithology for groundwater affluence (table 1).

\section{Methodology}

An overview of the techniques that was applied to analyze groundwater potential in the Broujerd region is demonstrated in figure 2 . The flowchart is made up of three parts: (1) data preparation, (2) mapping of groundwater potential applying statistical index and Dempster-Shafer theory techniques, and (3) validation of the produced models applying receiver operating characteristic curve.

\subsection{Datasets}

For understanding the connection among the spring locations and the impressive factors, mapping of 

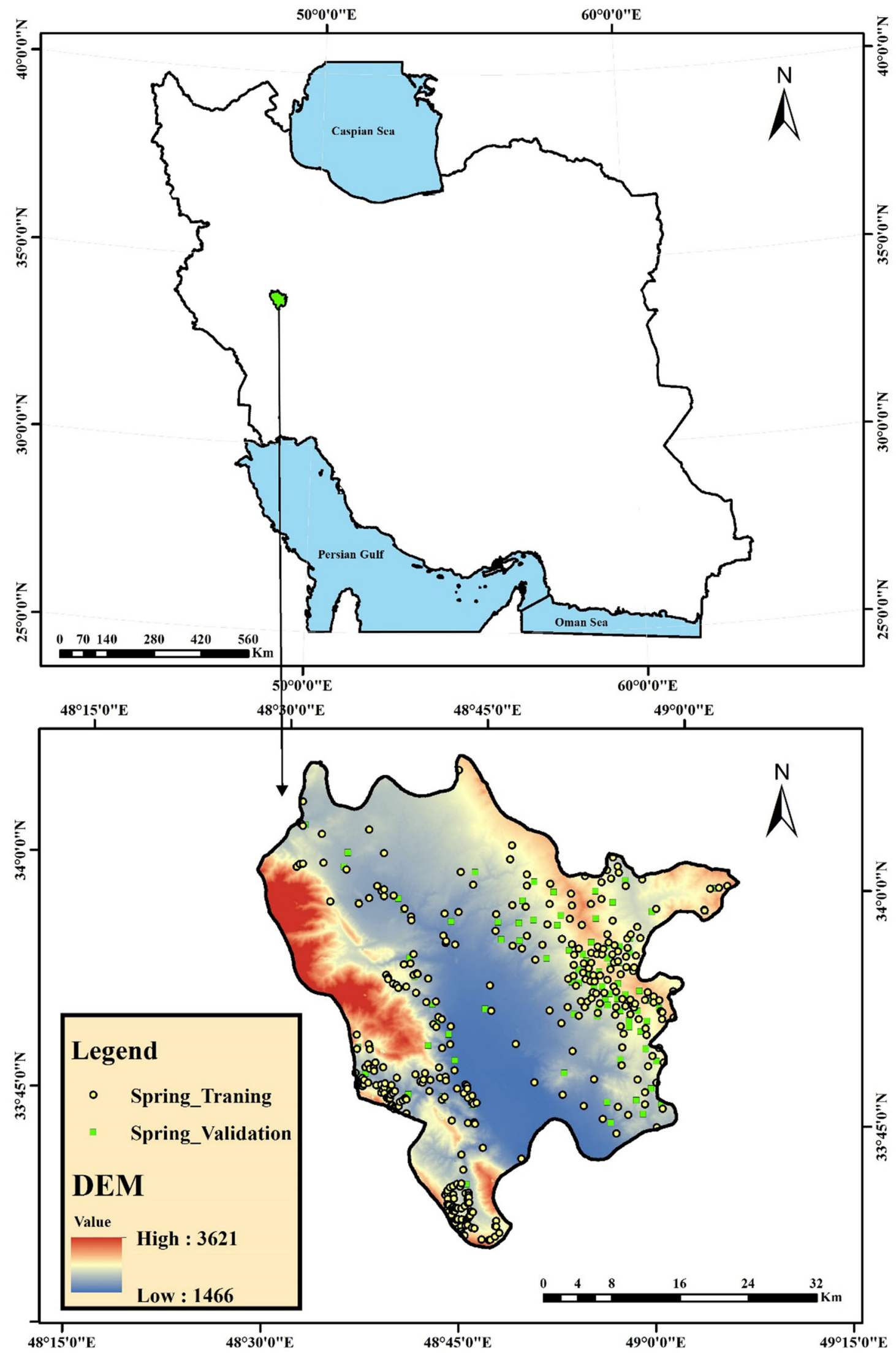

Figure 1. Location of the study area with spring locations map. 
Table 1. Lithology of the study area.

\begin{tabular}{lcll}
\hline Code & Formation & Lithology & Geological age \\
\hline $\mathrm{h}$ & - & Hornfels; andalusite; carbonate rocks & Mesozoic (Jurassic) \\
JKbs & - & Limestone & Mesozoic (Jurassic-Cretaceous) \\
KPAiai & - & Granite to diorite intrusive rocks & Mesozoic (Late Cretaceous) \\
Mf & Fars & Reefal Coral and Algal Limestone & Cenozoic (Miocene) \\
MJst & - & Meta-limestone, & Mesozoic (Triassic-Cretaceous) \\
& & meta-quartzarenite, phyllite & \\
Phh & Hamadan & and meta-volcanics & Mesozoic (Jurassic) \\
Qt2 & - & Phyllite, slate and meta-sandstone & Cenozoic (Quaternary)
\end{tabular}

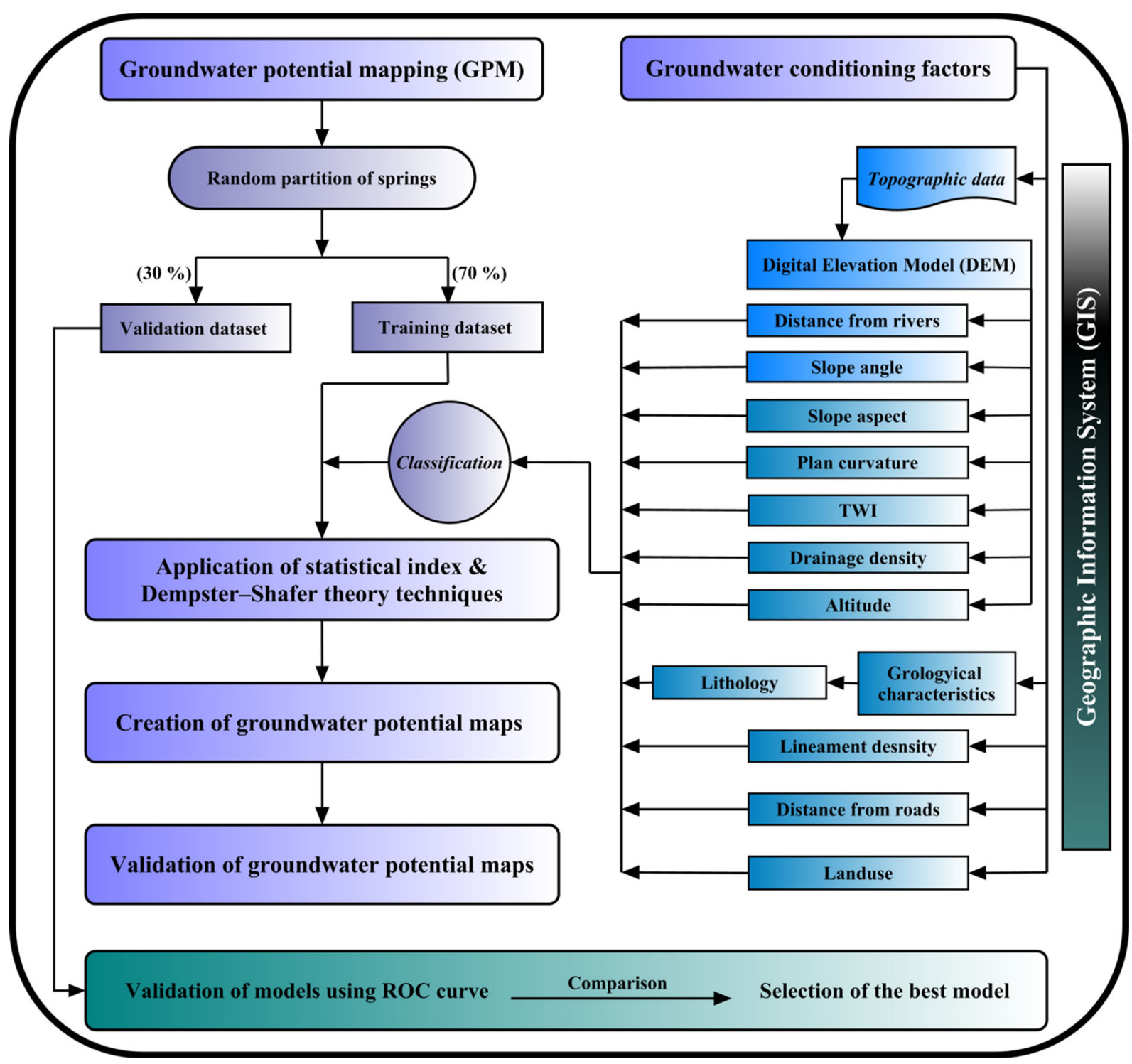

Figure 2. The flowchart of used methodology in the Broujerd Region, Iran. 
spring inventory is so useful. Firstly applying wide field surveys, 496 springs were discovered and were mapped in the Broujerd region (figure 1). Applying a haphazardly partition algorithm (Oh et al. 2011; Lee et al. 2012b) of the 496 spring locations, $70 \%$ were chosen for mapping of groundwater potential and the remaining 30\% were applied for validation. Assessment of various spring-relevant factors applying the spring inventory map is vital to define a groundwater potential map (GPM). In total, 11 spring-relevant factors were applied for calculations, which are altitude, slope aspect, slope angle, topographic wetness index (TWI), plan curvature, land use, distance from roads, distance from rivers, drainage density, lineament density, and lithology.

The digital elevation model (DEM) has been prepared by National Cartographic Center (NCC) using topography base points displaying the altitude values which were achieved from the 1:50,000 scale topographic maps and 20-m interval contours. For production altitude, slope aspect, slope angle, TWI, and plan curvature maps, the DEM was applied as the input layer (figure 2a-e). Altitude was built straightly from the 20-m DEM depending on the topographic maps and were grouped into six classes based on equal-interval classification scheme (figure 2a). Another impressive factor is slope aspect that was made applying the forenamed DEM and categorized into nine classes depending on usual standard classification (figure $2 \mathrm{~b}$ ). Slope has significant role for analyzing groundwater potential (Davoodi Moghaddam et al. 2015), therefore the slope angle map of the Broujerd region was constructed and categorized into five classes (figure 2c). Topography has an important effect on soil moisture, groundwater flow, and other hydrological conditions; therefore, the secondary topographic index such as TWI has been applied for describing spatial patterns of soil moisture (Beven and Kirkby 1979; Moore et al. 1991) (figure 2d).

Plan curvature is defined as the curvature of a contour line organized by dividing a horizontal plane with the surface (Moore and Burch 1986). The plan curvature map was made in SAGA-GIS software and categorized as flat, convex, and concave (figure 3e). By applying Landsat $7 \mathrm{ETM}^{+}$ (Enhanced Thematic Mapper Plus) images, the landuse map of the study area was prepared. According to figure $3(\mathrm{~g})$, these land use patterns are agriculture, orchard, forest, rangeland, and settlement. A large area of the Broujerd region $(42 \%)$ is covered by rangeland pattern.
Topographic database have been applied, to compute the distance to roads and rivers. The road and river buffers were computed in $500 \mathrm{~m}$ intervals, as displayed in (figure $3 g-h$ ). Different fracture patterns mirror the structure and lithology of the area and affect the drainage density and can be of big value to evaluate groundwater resources (Godebo 2005; Acharya et al. 2014; Bhuiyan 2015). Using river lines, the drainage density map was created and categorized into four classes (figure 3i). The density of geological lineaments influencing recharge and infiltration as a hydrogeological factor (Bhuiyan 2015). The lineament density was specified as the whole length of all recorded lineaments divided by the area under attention (Edet et al. 1998). In this study, lineament density map was classified into four categories (figure $3 \mathrm{j}$ ). The lithology factor is a momentous factor in predicting zones of groundwater potential. The lithology map was digitized applying a geological map (1:100,000 scale) in the ArcGIS environment. The Broujerd region consists of different patterns of lithological units and was grouped into seven classes.

For usage of SI and DST techniques, all the aforementioned groundwater related factors were modified to a raster grid with $20 \times 20 \mathrm{~m}$ cells.

\subsection{Application of models}

\subsubsection{Statistical index (SI)}

This technique is a bivariate statistical method. In this technique, a weight value for each categorical unit is described as the natural logarithm of the spring density in the categorical unit divided by the spring density in the whole map. This technique is dependent on the following equation (van Westen et al. 1997):

$$
W_{S I}=\ln \left(\frac{A i j}{A}\right)=\ln \left(\frac{S i j / S T}{T i j / T L}\right)
$$

where $W_{S I}$ is the value given to a definite category $i$ of parameter $j$; Aij spring density within category $i$ of parameter $j$; $A$ is all spring density within the whole map; $S i j$ is the number of springs in a definite category $i$ of parameter $j$; Tij is the number of pixels in a definite category $i$ of parameter $j$; $S T$ is the total number of springs in the whole map; $T L$, all pixels of the whole map. To carry out the SI analyzing, all maps are 



Figure 3. Groundwater effective factors maps in the Broujerd region, Iran: (a) altitude, (b) slope aspect, (c) slope angle, (d) topographic wetness index, (e) plan curvature, (f) land use, (g) distance from roads, (h) distance from rivers, (i) drainage density, (j) lineament density, and (k) lithology. 

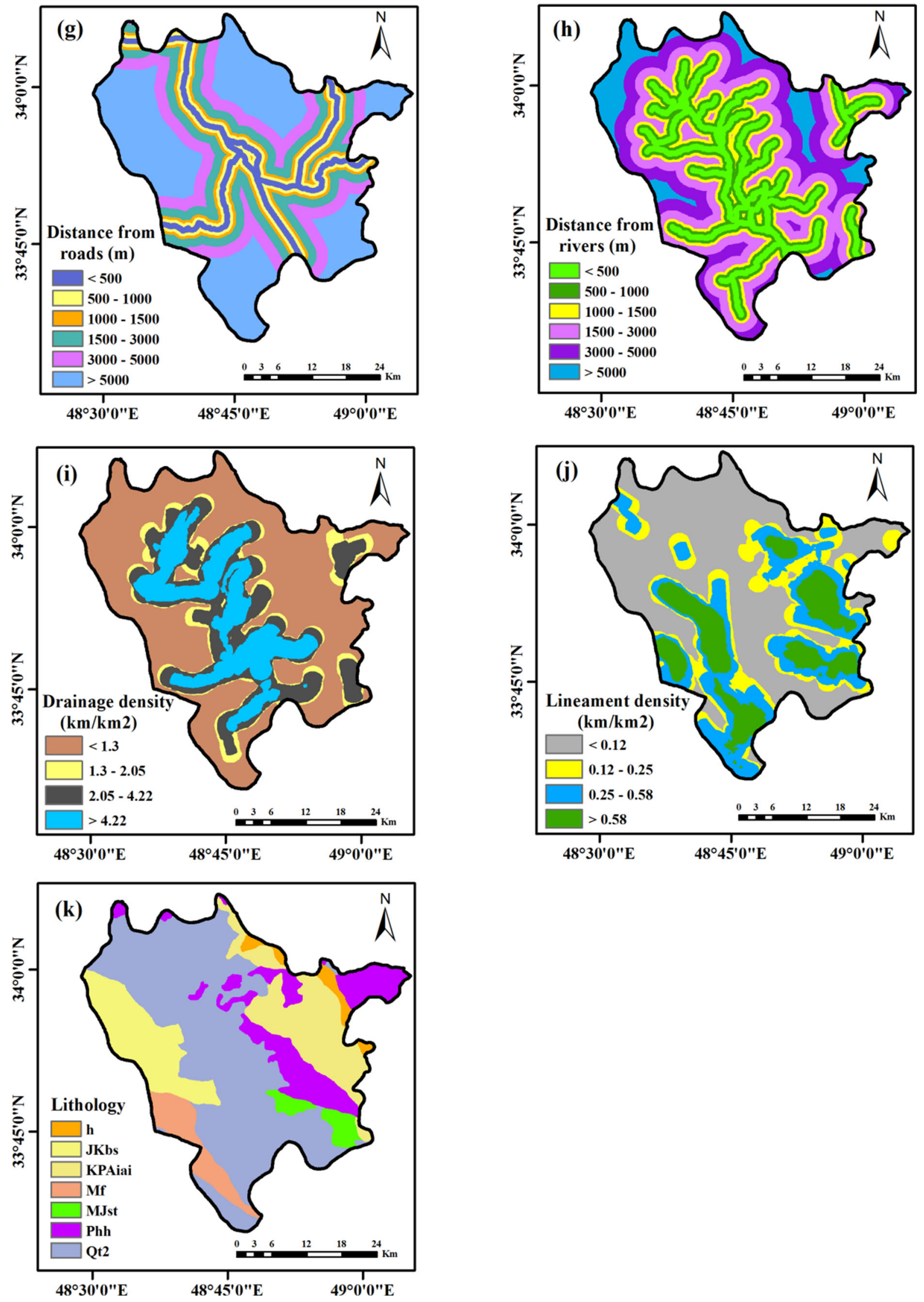

Figure 3. (Continued.) 
crossed and overlaid singly with the springs location map applying the ArcGIS 10.3 software, and the numbers of pixels forming the springs that fall into the different classes of the various maps are computed. The computed numbers of pixels are separated by the whole number of pixels for that chosen parameter to compute the density of the category. Until the spring density is more than normal, the weight value is positive and until it is less than normal, the weight value is negative. The last weight value gained from the modeling is investigated applying the weighted sum option of the spatial analyst tools part in ArcGIS software and the last groundwater potential map was produced.

\subsubsection{Dempster-Shafer theory (DST) model}

The Dempster Shafer theory is pursuant to Dempster law in popularization of Bayesian lower and upper probabilities (Dempster 1967, 1968). To use the DST technique, firstly, the thematic layers of groundwater impressive factors must be changed into evidential data layers. Then, they can be united to create a predictive groundwater potential map (GPM) applying the quantitative awareness of the spatial relation among groundwater impressive factors and springs.

In groudwater potential mapping using DST technique, each class of the impressive factors have a value of belief (Bel), value of disbelief (Dis), value of uncertainty (Unc), and value of plausibility (Pls) (values in range of $0-1$ ) (Althuwaynee et al. 2014; Pradhan et al. 2014). The first sections of the theory are indicated by Pls and Bel as upper and lower probability, respectively and basic probability assignment function characterizes a mapping of the power set to (0-1). For more details please refer to Park (2011) and Althuwaynee et al. (2014).

\section{Results and discussion}

\subsection{Statistical index (SI)}

Spatial relation among spring locations and each impressive factor applying the SI technique is displayed in table 2. The results of SI for the relation among spring incidence and altitude indicate that category of $1800-2200 \mathrm{~m}$ with a positive value (0.30) has the highest value of SI, and other categories have negative values. The results indicated that spring occurrence probability growth with the altitude increase in the Broujerd region, and then SI values reduce as the altitude becomes more than $2200 \mathrm{~m}$. For slope aspect impressive factor, springs are most affluent on northeast, east, and north facing having positive values of SI (0.59, 0.56 and 0.35 , respectively). So, the spring occurrence probability is more in these regions because in the Broujerd region, the drainage density, rivers, and faults are in the northeast-, east-, and northfacing parts. The statistical index (SI) value for slope angle displayed that ranges from 4.76 to 8.28 , and $8.28-15.53^{\circ}$ have the maximum effect on spring occurrence. The slope angle $>15.53^{\circ}$ has negative value because of slope grows, then the runoff grows (Israil et al. 2006), leading to lower infiltration (Jaiswal et al. 2003). The relation between topographic wetness index and groundwater potential displayed that category of slope angle $>7.2$ has the greatest value of SI (0.49). Fundamentally, the SI values display that the probability of spring incidence grows, when TWI increases. TWI is an impressive factor in this work because the infiltration of water relies on material attributes such as pore water pressure and permeability, and affects the soil strength. Concerning plan curvature, the SI value is positive (0.55) in concave slope and other slopes (flat and convex) show negative value. There is more water in concave slope and holds this water for more time mainly pending heavy rainfall (Lee and Pradhan 2006). Hence in comparison to the convex slope, it is more favourable for groundwater. Regarding land use, positive values of SI is recognized on forest (1.81) and agriculture (0.19) areas. These types of land use covers almost $0.42 \%$ and $31.45 \%$ of the study area, respectively. Distance from roads has tiny effect on spring occurrence. It has a very low probability to spring occurrence in distances $>3000 \mathrm{~m}$ from roads compared to the other categories. Differently, four categories of proximity to roads indicate powerful favour for spring occurrence. These categories are $<500 \mathrm{~m}(\mathrm{SI}=0.29)$, 500-1000 m (SI = 0.35), 1000-1500 m ( $\mathrm{SI}=0.17)$, and 1500-3000 (SI =0.14). The aforesaid results showed that roads indirectly affect the porosity and permeability of the terrain. Regarding distance from rivers, distance among 1500-3000 m only have a positive value of SI (0.26), indicating a very big probability of spring incidence. The drainage density $1.3-2.05 \mathrm{~km} / \mathrm{km}^{2}$ has an SI value of 0.22 , that means that the properties of this category have the most powerful relation with spring incidence, whereas class of $>4.22$ has an SI value of -0.47 . 
Table 2. Spatial relationship between each effective factor and spring locations using SI and DST models.

\begin{tabular}{|c|c|c|c|c|c|c|c|}
\hline Class & $\begin{array}{l}\text { No. pixels } \\
\text { in domain }\end{array}$ & $\begin{array}{l}\text { No. of } \\
\text { Springs }\end{array}$ & Bel & Dis & Unc & Pls & SI \\
\hline \multicolumn{8}{|c|}{ Altitude (m) } \\
\hline$<1800$ & 635631 & 88 & 0.25 & 0.19 & 0.56 & 0.81 & -0.30 \\
\hline $1800-2200$ & 834177 & 210 & 0.45 & 0.12 & 0.43 & 0.88 & 0.30 \\
\hline $2200-2600$ & 294041 & 49 & 0.30 & 0.17 & 0.53 & 0.83 & -0.11 \\
\hline $2600-3000$ & 69023 & 0 & 0.00 & 0.18 & 0.82 & 0.82 & - \\
\hline $3000-3400$ & 25869 & 0 & 0.00 & 0.17 & 0.83 & 0.83 & - \\
\hline$>3400$ & 3656 & 0 & 0.00 & 0.17 & 0.83 & 0.83 & - \\
\hline \multicolumn{8}{|c|}{ Slope aspect } \\
\hline Flat & 19378 & 0 & 0.00 & 0.11 & 0.89 & 0.89 & - \\
\hline North & 190024 & 50 & 0.17 & 0.11 & 0.72 & 0.89 & 0.35 \\
\hline Northeast & 222163 & 75 & 0.22 & 0.10 & 0.68 & 0.90 & 0.59 \\
\hline East & 212444 & 69 & 0.21 & 0.10 & 0.69 & 0.90 & 0.56 \\
\hline Southeast & 217036 & 34 & 0.10 & 0.11 & 0.79 & 0.89 & -0.17 \\
\hline South & 268688 & 32 & 0.08 & 0.12 & 0.81 & 0.88 & -0.45 \\
\hline Southwest & 315185 & 47 & 0.10 & 0.12 & 0.79 & 0.88 & -0.22 \\
\hline West & 253498 & 21 & 0.05 & 0.12 & 0.83 & 0.88 & -0.81 \\
\hline Northwest & 163981 & 19 & 0.07 & 0.12 & 0.81 & 0.88 & -0.48 \\
\hline \multicolumn{8}{|c|}{ Slope angle } \\
\hline$<2.26$ & 378115 & 27 & 0.08 & 0.23 & 0.69 & 0.77 & -0.96 \\
\hline $2.26-4.76$ & 381260 & 65 & 0.18 & 0.20 & 0.61 & 0.80 & -0.09 \\
\hline $4.76-8.28$ & 368312 & 100 & 0.29 & 0.18 & 0.53 & 0.82 & 0.38 \\
\hline $8.28-15.53$ & 368195 & 109 & 0.32 & 0.17 & 0.51 & 0.83 & 0.46 \\
\hline$>15.53$ & 366515 & 46 & 0.13 & 0.22 & 0.65 & 0.78 & -0.40 \\
\hline \multicolumn{8}{|l|}{ TWI } \\
\hline$<4.92$ & 451907 & 58 & 0.17 & 0.27 & 0.55 & 0.73 & -0.37 \\
\hline $4.92-5.9$ & 488550 & 70 & 0.19 & 0.27 & 0.54 & 0.73 & -0.26 \\
\hline $5.9-7.2$ & 481415 & 85 & 0.23 & 0.25 & 0.51 & 0.75 & -0.05 \\
\hline$>7.2$ & 440525 & 134 & 0.40 & 0.20 & 0.39 & 0.80 & 0.49 \\
\hline \multicolumn{8}{|c|}{ Plan curvature $(100 / \mathrm{m})$} \\
\hline Concave & 276014 & 89 & 0.54 & 0.29 & 0.17 & 0.71 & 0.55 \\
\hline Flat & 1289364 & 230 & 0.30 & 0.36 & 0.34 & 0.64 & -0.04 \\
\hline Convex & 297019 & 28 & 0.16 & 0.36 & 0.48 & 0.64 & -0.68 \\
\hline \multicolumn{8}{|l|}{ Land use } \\
\hline Agriculture & 585888 & 132 & 0.13 & 0.18 & 0.69 & 0.82 & 0.19 \\
\hline Orchard & 456165 & 66 & 0.08 & 0.21 & 0.70 & 0.79 & -0.25 \\
\hline Forest & 7865 & 9 & 0.64 & 0.20 & 0.16 & 0.80 & 1.82 \\
\hline Rangeland & 782012 & 137 & 0.10 & 0.21 & 0.69 & 0.79 & -0.06 \\
\hline Urban & 30467 & 3 & 0.06 & 0.20 & 0.74 & 0.80 & -0.64 \\
\hline \multicolumn{8}{|c|}{ Distance from road $(\mathrm{m})$} \\
\hline$<500$ & 156042 & 39 & 0.20 & 0.16 & 0.64 & 0.84 & 0.29 \\
\hline $500-1000$ & 139561 & 37 & 0.21 & 0.16 & 0.63 & 0.84 & 0.35 \\
\hline $1000-1500$ & 127211 & 28 & 0.18 & 0.16 & 0.66 & 0.84 & 0.17 \\
\hline $1500-3000$ & 327627 & 70 & 0.17 & 0.16 & 0.67 & 0.84 & 0.14 \\
\hline $3000-5000$ & 331532 & 44 & 0.11 & 0.18 & 0.72 & 0.82 & -0.34 \\
\hline$>5000$ & 780424 & 129 & 0.13 & 0.18 & 0.69 & 0.82 & -0.12 \\
\hline \multicolumn{8}{|c|}{ Distance from rivers (m) } \\
\hline$<500$ & 309903 & 46 & 0.14 & 0.17 & 0.69 & 0.83 & -0.23 \\
\hline $500-1000$ & 268529 & 46 & 0.16 & 0.17 & 0.67 & 0.83 & -0.08 \\
\hline $1000-1500$ & 226905 & 41 & 0.17 & 0.17 & 0.66 & 0.83 & -0.03 \\
\hline $1500-3000$ & 487683 & 118 & 0.23 & 0.15 & 0.62 & 0.85 & 0.26 \\
\hline
\end{tabular}


Table 2. (Continued.)

\begin{tabular}{|c|c|c|c|c|c|c|c|}
\hline Class & $\begin{array}{l}\text { No. pixels } \\
\text { in domain }\end{array}$ & $\begin{array}{l}\text { No. of } \\
\text { Springs }\end{array}$ & Bel & Dis & Unc & Pls & $\mathrm{SI}$ \\
\hline $3000-5000$ & 371678 & 68 & 0.17 & 0.17 & 0.66 & 0.83 & -0.02 \\
\hline$>5000$ & 197699 & 28 & 0.13 & 0.17 & 0.70 & 0.83 & -0.27 \\
\hline \multicolumn{8}{|c|}{ Drainage density $\left(\mathrm{km} / \mathrm{km}^{2}\right)$} \\
\hline$<1.3$ & 1064584 & 224 & 0.29 & 0.21 & 0.50 & 0.79 & 0.12 \\
\hline $1.3-2.05$ & 129710 & 30 & 0.32 & 0.25 & 0.43 & 0.75 & 0.22 \\
\hline $2.05-4.22$ & 334806 & 54 & 0.22 & 0.26 & 0.51 & 0.74 & -0.14 \\
\hline$>4.22$ & 333297 & 39 & 0.16 & 0.28 & 0.56 & 0.72 & -0.47 \\
\hline \multicolumn{8}{|c|}{ Lineament density $\left(\mathrm{km} / \mathrm{km}^{2}\right)$} \\
\hline$<0.12$ & 927894 & 37 & 0.04 & 0.41 & 0.55 & 0.59 & -1.54 \\
\hline $0.12-0.25$ & 268470 & 54 & 0.20 & 0.23 & 0.57 & 0.77 & 0.08 \\
\hline $0.25-0.58$ & 369251 & 143 & 0.38 & 0.17 & 0.45 & 0.83 & 0.73 \\
\hline$>0.58$ & 296782 & 113 & 0.38 & 0.19 & 0.44 & 0.81 & 0.71 \\
\hline \multicolumn{8}{|l|}{ Lithology } \\
\hline $\mathrm{h}$ & 39570 & 8 & 0.33 & 0.34 & 0.33 & 0.66 & 0.08 \\
\hline JKbs & 224097 & 12 & 0.09 & 0.37 & 0.54 & 0.63 & -1.25 \\
\hline KPAiai & 274768 & 96 & 0.58 & 0.29 & 0.13 & 0.71 & 0.63 \\
\hline Mf & 102975 & 64 & 1.03 & 0.29 & -0.32 & 0.71 & 1.20 \\
\hline MJst & 53256 & 4 & 0.12 & 0.35 & 0.53 & 0.65 & -0.91 \\
\hline $\mathrm{Phh}$ & 246891 & 27 & 0.18 & 0.36 & 0.46 & 0.64 & -0.53 \\
\hline Qt2 & 920840 & 136 & 0.24 & 0.41 & 0.35 & 0.59 & -0.23 \\
\hline
\end{tabular}

For this factor, as the drainage density grows, the spring frequency commonly reduces. The drainage density relies on the existing local and regional fracture patterns and characteristics of bedrocks (Pourghasemi and Beheshtirad 2014). Considering the case of lineament density, results showed that $0.25-0.58$ and $>0.58 \mathrm{~km} / \mathrm{km}^{2}$ classes have values weights (SI) of 0.73 and 0.71 , respectively. In contrast, for the lineament density $<0.12$, relation among spring incidence and lineaments demonstrates a slight probability of spring incidence. Linearly fractured regions on geologic structure of an area such as, dykes and faults are lineaments and they can control the water movement among subsurface and surface. Regarding lithology, the statistical values were positive in Mf (coral-reef and algal limestone), KPAiai (granite to diorite intrusive rocks) and $\mathrm{h}$ (contact metamorphic rocks) classes. Meanwhile, class Mf has the most probability for spring incidence with value of 1.20 ; due to lithological formations. Finally, groundwater potential map applying SI technique was built by the following equation:

$$
\begin{aligned}
\mathrm{GPM}_{\mathrm{SI}}= & (0.30 \text { altitude })+(0.59 \text { slope aspect }) \\
& +(0.46 \text { slope angle })+(0.49 \text { TWI })
\end{aligned}
$$

$$
\begin{aligned}
& +(0.55 \text { plan curvature })+(1.82 \text { landuse }) \\
& +(0.35 \text { distance from roads }) \\
& +(0.26 \text { distance from rivers }) \\
& +(0.22 \text { drainage density }) \\
& +(0.73 \text { lineament density }) \\
& +(1.20 \text { lithology })
\end{aligned}
$$

\subsection{Dempster-Shafer theory (DST)}

The outcomes of spatial relation among groundwater occurrence and impressive factors applying Dempster-Shafer theory (disbelief, belief, plausibility, and uncertainty) technique is displayed in table 2. Based on table 2, the classes of the impressive factors which have a higher belief (Bel) values, have more efficacy on the groundwater potential. For instance, in association with altitude, 1800 2200 and $2200-2600 \mathrm{~m}$ classes had the greatest belief values $(0.45$ and 0.30$)$.

The integrated results of Dempster-Shafer theory technique is demonstrated in figure 4. After comparing belief map (figure 4a) with disbelief map (figure $4 \mathrm{~b}$ ), the results indicated that enormous groundwater potential was there for the regions having small values of disbelief and high values 

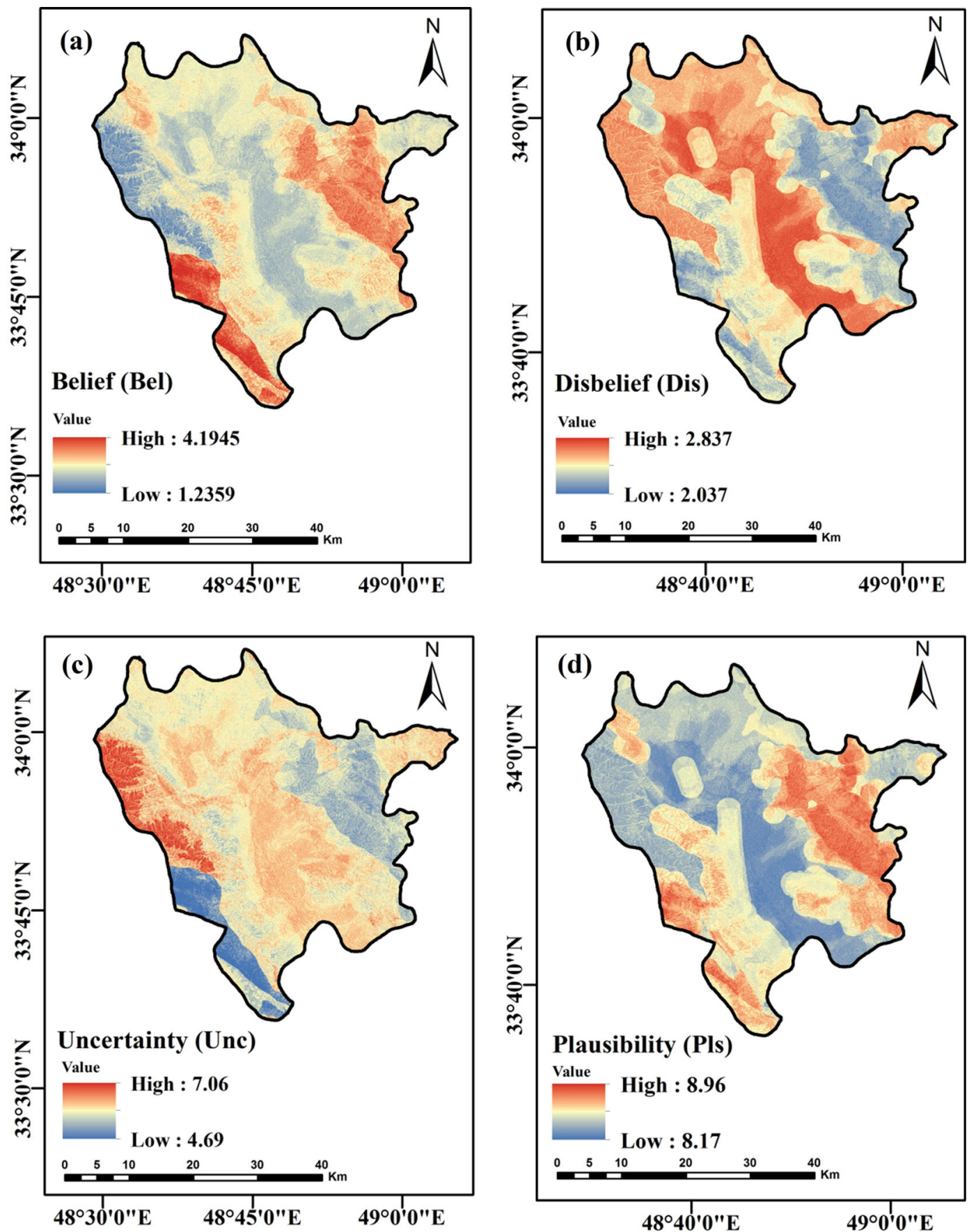

Figure 4. Integrated results of Dempster-Shafer theory technique in the Broujerd region, Iran; (a) belief, (b) disbelief, (c) uncertainty, and (d) plausibility.

of belief for the incidence. The uncertainty map (figure 4c) displayed absence of information for providing an actual proof for spring incidences. The enormous uncertainty degrees were in the regions where belief degrees were small. The plausibility map (figure 4d) display enormous degrees for regions where both belief and uncertainty degrees are enormous. In agreement with results of Althuwaynee et al. (2014) and Pradhan et al. (2014), our results indicated that the dominant benefit of Dempster-Shafer theory is that, the usage of this model not only lets the predictive mapping of desirable regions, but also allows calculating the degrees of uncertainty in the prediction. Moreover, pursuant to outcomes reported by Park (2011) and Lee et al. (2012a), DempsterShafer theory technique provide a group of mass functions containing Bel, Dis, Unc and Pls. Therefore, the outcomes of this technique illustrate quantitative relations among impressive factors 

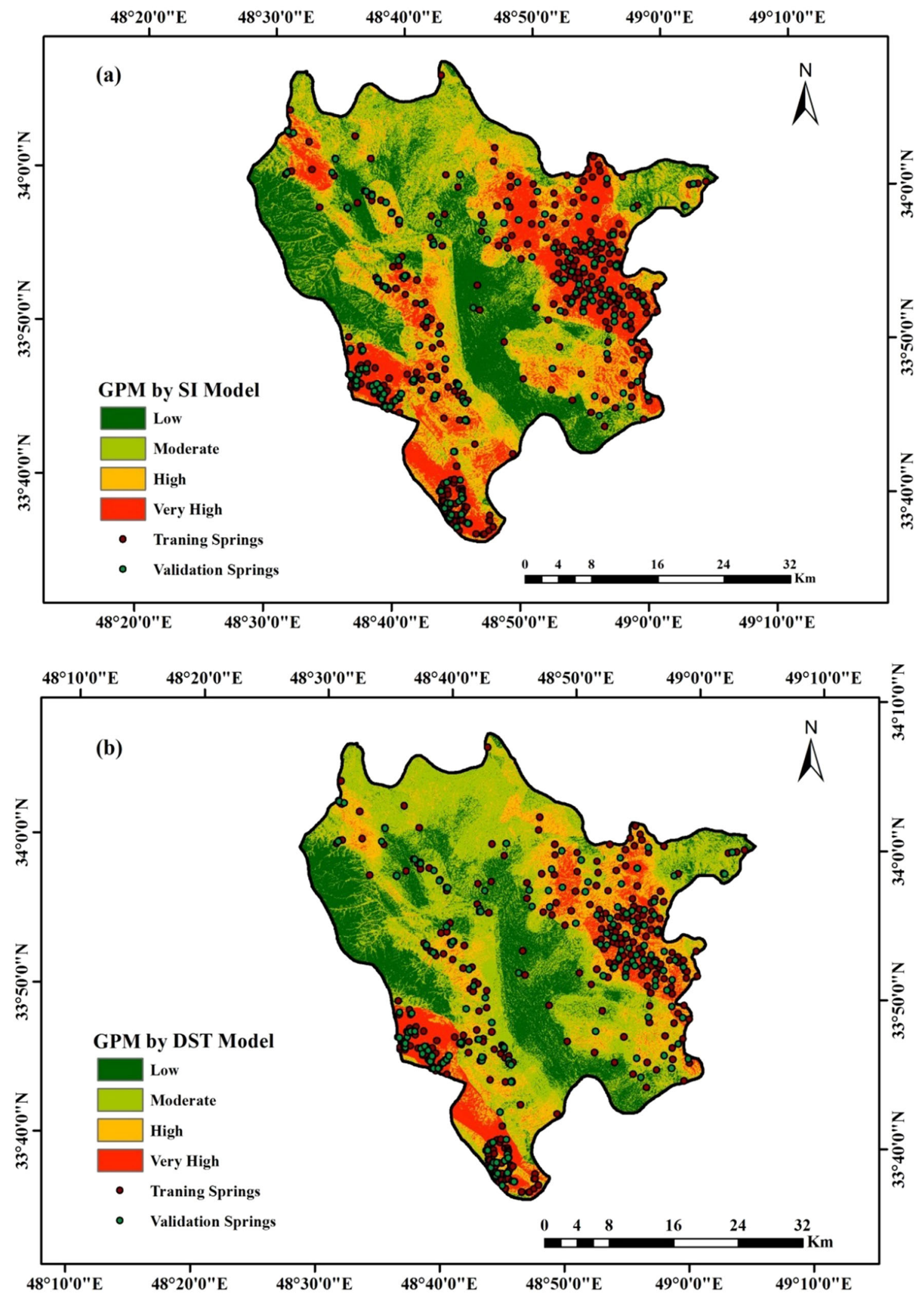

Figure 5. Groundwater potential maps (GPMs) produced by (a) statistical index and (b) Dempster-Shafer theory techniques in the Broujerd region, Iran. 

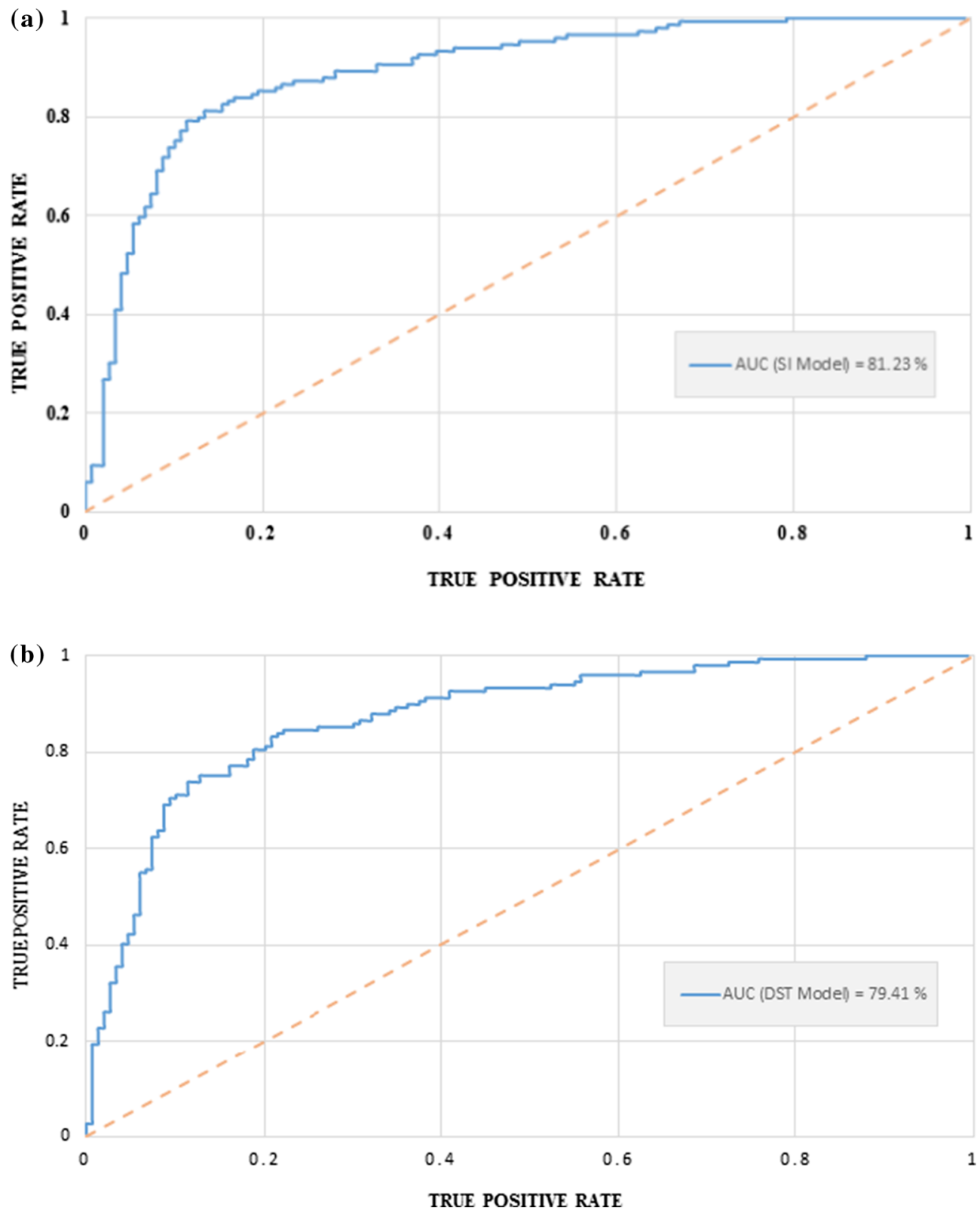

Figure 6. Prediction rate curves for the groundwater potential maps by (a) SI and (b) DST techniques in the Broujerd region, Iran.

and spring occurrence by calculating the degree of uncertainty. In the end, the groundwater potential map (GPM) applying DST technique was constructed applying the following equation (figure 5):

$$
\begin{aligned}
& \mathrm{GPM}_{\mathrm{DST}}=\left(\left[\text { Altitude }_{\mathrm{Bel}}\right]\right)+\left(\left[\text { Slope }_{\text {Aspect }}{ }_{\mathrm{Bel}}\right]\right) \\
& +\left(\left[\text { Slope Angle } \mathrm{Bel}_{\mathrm{Bel}}\right]\right)+\left(\left[\mathrm{TWI}_{\mathrm{Bel}}\right]\right) \\
& +\left(\left[\text { Plan Curvature }{ }_{\text {Bel }}\right]\right) \\
& +\left(\left[\text { Landuse }_{\text {Bel }}\right]\right) \\
& +\left(\left[\text { Distance from Roads }_{\mathrm{Bel}}\right]\right) \\
& +\left(\left[\text { Distance from Rivers }_{\text {Bel }}\right]\right)
\end{aligned}
$$

$$
\begin{aligned}
& +\left(\left[\text { Drainage Density }_{\text {Bel }}\right]\right) \\
& +\left(\left[\text { Lineament Density }_{\text {Bel }}\right]\right) \\
& +\left(\left[\text { Lithology }_{\text {Bel }}\right]\right)
\end{aligned}
$$

In this research, two groundwater potential maps, statistical index and Dempster-Shafer theory (figure $6 \mathrm{a}-\mathrm{b})$, were produced in ArcGIS software into four categories and pursuant to natural break categorization method into low (poor), moderate, high (good), and very high (very good) potential zones (table 3) (Ozdemir 2011a; Naghibi and Pourghasemi 2015). Based on the GPMs of SI and DST, poor zone of GPMs covered $24.22 \%$, and 
Table 3. The distribution of the spring potential values and areas with respect to the groundwater spring occurrence potential zones.

\begin{tabular}{lcc}
\hline $\begin{array}{l}\text { Spring potential } \\
\text { zoning }\end{array}$ & $\begin{array}{c}\text { SI model } \\
\text { range }\end{array}$ & $\begin{array}{c}\text { Dempster-Shafer model } \\
\text { Area }(\%)\end{array}$ \\
\hline Low & $(-6.07)-(-2.66)$ & 24.22 \\
Moderate & $(-2.66)-(-0.94)$ & 31.85 \\
High & $(-0.94)-(0.88)$ & 26.34 \\
Very high & $(0.88)-(5.22)$ & 17.59 \\
\hline \multicolumn{3}{c}{ DST model } \\
\hline Low & Range & Area (\%) \\
Moderate & $(1.24)-(2.07)$ & 23.74 \\
High & $(2.07)-(2.48)$ & 39.66 \\
Very high & $(2.48)-(2.96)$ & 24.09 \\
\hline
\end{tabular}

$23.74 \%$ of the Broujerd region, respectively, whenever the sum of good and very good zones for SI and DST are $43.93 \%$, and $36.3 \%$, respectively. Therefore, the results showed that DST have lowest values of area for high and very high classes compared to SI.

\section{Validation of groundwater potential maps}

The most significant process of modeling is considered to be validation and without which the models will have no scientific importance (Chung and Fabbri 2003; Nampak et al. 2014). For determining the validity of the groundwater potential maps that were produced in this study using statistical index and Dempster-Shafer theory, the receiver operating characteristics (ROC) curve was applied using MedCalc 15.8 software (Mohammady et al. 2012; Ozdemir and Altural 2013; Pourghasemi et al. 2013; Rahmati et al. 2016). ROC curve method is a usual technique used to specify the punctuality of a diagnostic exam (Egan 1975). This curve could be a demonstrated picture of the exchange among the false negative and positive rates for every conceivable cutoff value. It plots the true positive rate on the $\mathrm{Y}$-axis and the false positive rate on the X-axis (Negnevitsky 2002; Davoodi Moghaddam et al. 2015). Pursuant to Yesilnacar (2005), the qualitative relation among prediction punctuality and AUC can be categorized into the following groups: 0.9-1 (excellent); 0.8-0.9 (very good); 0.70.8 (good); 0.6-0.7 (average); and 0.5-0.6 (poor). In this research, the remaining 149 spring loca- tions $(30 \%$ which were not applied and pending in the model building process) were applied to verify the groundwater potential map. The AUC value of the ROC curves for SI and DST models were 0.8123 and 0.7941 , and the prediction accuracy were $81.23 \%$ and $79.41 \%$, respectively (figure $6)$. Hence, it is concluded that SI technique indicated very good accuracy in groundwater potential analysing and DST technique showed good performance in groundwater potential zoning in the Broujerd region. Meanwhile there are some drawbacks on bivariate statistical models that are given below:

van Westen et al. (1997) reported that one of the most important limitations of bivariate statistical models is that they have used conditional independence assumption. By the way, these models are related to groundwater spring locations and effective factors, seriously. Another important disadvantage of bivariate statistical models as presented by Pradhan et al. (2013) is that we could not calculate the importance of each factor and their role on output maps. So, the mentioned drawbacks can be effective on each finding in different cases.

\section{Conclusions}

All around the world, groundwater is one of the utmost significant natural resources. Accordingly, prediction and recognition of spatial repartition of potential zones for exploring groundwater have turned into an important subject for private, government, and research organizations worldwide. The present research was intended to assess the 
performance of the SI and DST approaches for predictive modeling of groundwater potentiality and explored the relations between groundwater conditioning factors and groundwater potential of Broujerd region, Lorestan Province, Iran, using spring locations. Hence, the SI and DST techniques both indicate the potential zones of groundwater, and also show the most important classes of each conditioning factor. Also, the SI and DST techniques showed very good and good performance in groundwater potential analyzing in the Broujerd region, respectively. In addition, the SI method not only has a slightly better performance than the DST technique, but also does not have a complicated calculation such as DST model. On the other hand, pursuant to obtained outcomes reported by various researchers, the DST method has considered the uncertainty and probability for a spatial distribution of groundwater potentiality and present quantitative relationships between impressive factors and springs occurrence by modeling the degree of uncertainty.

Moreover, this research indicate that the SI and DST techniques are appropriate for analysing of groundwater potential and simulating the complicated relation among groundwater incidence and groundwater conditioning factors, which permits analysis of both systemic and stochastic uncertainty. In addition, it can be realized that SI and DST techniques are very beneficial for groundwater potential analysing and can be practical for waterresource management experts and we believe that the outcomes acquired from our research prepare a significant contribution to the literature on groundwater.

\section{Acknowledgements}

The authors would like to thank Iranian Meteorological Organization and Geological Survey of Iran (GSI) for giving meteorological data of Broujerd Station and geology map. Also, authors would like to thank two anonymous reviewers and editorial positive comments.

\section{References}

Acharya T, Prasad R and Chakrabarti S 2014 Evaluation of regional fracture properties for groundwater development using hydrolithostructural domain approach in variably fractured hard rocks of Purulia district, West Bengal, India; J. Earth Syst. Sci. 123 517-529.
Agarwal E, Agarwal R, Garg R D and Garg P K 2013 Delineation of groundwater potential zone: An AHP/ANP approach; J. Earth Syst. Sci. 122 887-898.

Al-Abadi A M 2015 Modeling of groundwater productivity in northeastern Wasit Governorate, Iraq using frequency ratio and Shannon's entropy models; Appl. Water Sci. 7(2) 699-716, https://doi.org/10.1007/ s13201-015-0283-1.

Althuwaynee O F, Pradhan B, Park H J and Lee J H 2014 A novel ensemble bivariate statistical evidential belief function with knowledge-based analytical hierarchy process and multivariate statistical logistic regression for landslide susceptibility mapping; Catena 114 21-36.

Azkune G, Almeida A, López-de-Ipiõa D and Chen L 2015 Extending knowledge-driven activity models through data-driven learning techniques; Expert Syst. Appl. 42 3115-3128.

Bastani M, Kholghi M and Rakhshandehroo G R 2010 Inverse modeling of variable-density groundwater flow in a semi-arid area in Iran using a genetic algorithm; Hydrogeol. J. 18 1191-1203.

Beven K and Kirkby M J 1979 A physically based, variable contributing area model of basin hydrology; Hydrol. Sci. Bull. 24 43-69.

Bhuiyan C 2015 Hydrological characterization of geological lineaments: A case study from the Aravalli terrain, India; Hydrogeol. J. 23 673-686.

Chung C F and Fabbri A G 2003 Validation of spatial prediction models for landslide hazard mapping; Nat. Hazards 30 451-472.

Corsini A, Cervi F and Ronchetti F 2009 Weight of evidence and artificial neural networks for potential groundwater spring mapping: An application to the Mt. Modino area (Northern Apennines, Italy); Geomorphology 111 79-87.

Davoodi Moghaddam D, Rezaei M, Pourghasemi H R, Pourtaghie Z S and Pradhan B 2015 Groundwater spring potential mapping using bivariate statistical model and GIS in the Taleghan watershed, Iran; Arab. J. Geosci. 8 913-929.

Dempster A P 1967 Upper and lower probabilities induced by a multivalued mapping; Ann. Math. Stat. 38 325339.

Dempster A P 1968 Generalization of Bayesian inference; J. Royal Stat. Soc.: Ser. B 30 205-247.

Edet A, Okereke C S, Teme S C and Esu E O 1998 Application of remote-sensing data to groundwater exploration: A case study of the Cross River State, southeastern Nigeria; Hydrogeol. J. 6 394-404.

Egan J P 1975 Signal detection theory and ROC analysis; Academic, New York, pp. 266-268.

Godebo T R 2005 Application of remote sensing and GIS for geological investigation and groundwater potential zone identification, southeastern Ethiopian Plateau, Bale Mountains and the surrounding areas, Addis Ababa University, Dissertation.

Israil M, Al-hadithi M, Singhal D C, Kumar B, Rao M S and Verma K 2006 Groundwater resources evaluation in the Piedmont zone of Himalaya, India, using isotope and GIS technique; J. Spat. Hydrol. 6(1) 34-38.

Jaiswal R K, Mukherjee S, Krishnamurthy J and Saxena R 2003 Role of remote sensing and GIS techniques for generation of groundwater prospect zones towards rural 
development - an approach; Int. J. Remote Sens. 24(5) 993-1008.

Jha M K, Chowdary V M and Chowdhury A 2010 Groundwater assessment in Salboni Block, West Bengal (India) using remote sensing, geographical information system and multi-criteria decision analysis techniques; Hydrogeol. J. 18 1713-1728.

Lee S and Pradhan B 2006 Probabilistic landslide hazards and risk mapping on Penang Island, Malaysia; J. Earth Syst. Sci. 115(6) 661-667.

Lee S, Hwang J and Park I 2012a Application of data-driven evidential belief functions to landslide susceptibility mapping in Jinbu, Korea; Catena 100 15-30.

Lee S, Kim Y S and Oh H J 2012b Application of a weightsof-evidence method and GIS to regional groundwater productivity potential mapping; J. Environ. Manag. 96 91-105.

Mahesvaran G, Selvarani A G and Elangovan K 2016 Groundwater resource exploration in Salem district, Tamil Nadu using GIS and remote sensing; J. Earth Syst. Sci. 125 311-328.

Manap M A, Nampak H, Pradhan B, Lee S, Sulaiman W N A and Ramli M F 2012 Application of probabilistic-based frequency ratio model in groundwater potential mapping using remote sensing data and GIS; Arab. J. Geosci. 7(2) 711-724, https://doi.org/10.1007/s12517-012-0795-z.

Masoud M H and El Osta M M 2016 Evaluation of groundwater vulnerability in El-Bahariya Oasis, Western Desert, Egypt, using modelling and GIS techniques: A case study; J. Earth Syst. Sci. 125(6) 1139-1155.

Mogaji K A, Omosuyi G O, Adelusi A O and Lim H S 2016 Application of GIS-based evidential belief function model to regional groundwater recharge potential zones mapping in hardrock geologic terrain; Environ. Process. 3(1) 93123.

Mohammady M, Pourghasemi H R and Pradhan B 2012 Landslide susceptibility mapping at Golestan Province, Iran: A comparison between frequency ratio, DempsterShafer, and weights-of-evidence models; J. Asian Earth Sci. 61 221-236.

Mondal N C, Das S N and Singh V S 2008 Integrated approach for identification of potential groundwater zones in Seethanagaram Mandal of Vizianagaram District, Andhra Pradesh, India; J. Earth Syst. Sci. 117(2) 133144.

Moore I D and Burch G J 1986 Sediment transport capacity of sheet and rill flow: Application of unit stream power theory; Water Resour. 22 1350-1360.

Moore I D, Grayson R B and Ladson A R 1991 Digital terrain modelling: A review of hydrological, geomorphological, and biological applications; Hydrol. Process. 4 3-30.

Naghibi S A and Pourghasemi H R 2015 A comparative assessment between three machine learning models and their performance comparison by bivariate and multivariate statistical methods in groundwater potential mapping; Water Resour. Manag. 29 5217-5236.

Naghibi S A, Pourghasemi H R, Pourtaghie Z S and Rezaei A 2015 Groundwater qanat potential mapping using frequency ratio and Shannon's entropy models in the Moghan Watershed, Iran; Earth Sci. Inform. 8 171-186.

Nampak H, Pradhan B and Manap M A 2014 Application of GIS based data driven evidential belief function model to predict groundwater potential zonation; J. Hydrol. 513 283-300, https://doi.org/10.1016/j.jhydrol.2014.02.053.

Negnevitsky M 2002 Artificial intelligence: A guide to intelligent systems, Addison-Wesley/Pearson, Harlow, England, 394p.

Nosrati K and Eeckhaut M V D 2012 Assessment of groundwater quality using multivariate statistical techniques in Hashtgerd Plain, Iran; Environ. Earth Sci. $65331-$ 344.

Oh H J, Kim Y S, Choi J K, Park E and Lee S 2011 GIS mapping of regional probabilistic groundwater potential in the area of Pohang City, Korea; J. Hydrol. 399158 172.

Ozdemir A 2011a GIS-based groundwater spring potential mapping in the Sultan Mountains (Konya, Turkey) using frequency ratio, weights of evidence and logistic regression methods and their comparison; J. Hydrol. 411(3-4) 290308.

Ozdemir A 2011b Using a binary logistic regression method and GIS for evaluating and mapping the groundwater spring potential in the Sultan Mountains (Aksehir, Turkey); J. Hydrol. 405 123-136.

Ozdemir A and Altural T 2013 A comparative study of frequency ratio, weights of evidence and logistic regression methods for landslide susceptibility mapping: Sultan Mountains, SW Turkey; J. Asian Earth Sci. 64 180-197.

Park I, Kim Y and Lee S 2014 Groundwater productivity potential mapping using evidential belief function; Groundwater 52 201-207.

Park N W 2011 Application of Dempster-Shafer theory of evidence to GIS-based landslide susceptibility analysis; Environ. Earth Sci. 62(2) 367-376.

Pourghasemi H R and Beheshtirad M 2014 Assessment of a data-driven evidential belief function model and GIS for groundwater potential mapping in the Koohrang Watershed, Iran; Geocarto Int. 30(6) 662-685, https://doi.org/ 10.1080/10106049.2014.966161.

Pourghasemi H R, Moradi H R and Fatemi Aghda S M 2013 Landslide susceptibility mapping by binary logistic regression, analytical hierarchy process, and statistical index models and assessment of their performances; Nat. Hazards 69 749-779.

Pourtaghi Z S and Pourghasemi H R 2015 GIS-based groundwater spring potential assessment and mapping in the Birjand Township, southern Khorasan Province, Iran; Hydrogeol. J. 22 643-662.

Pradhan A M S, Dawadi A and Kim Y T 2013 Use of different bivariate statistical landslide susceptibility methods: A case study of Kulekhani watershed Nepal; J. Nepal Geol. Soc. 44 1-12.

Pradhan B, Abokharima M H, Neamah Jebur M and Shafapour Tehrany M 2014 Land subsidence susceptibility mapping at Kinta Valley (Malaysia) using the evidential belief function model in GIS; Nat. Hazards 73(2) 10191042, https://doi.org/10.1007/s11069-014-1128-1.

Rahmati O, Nazari Samani A, Mahdavi M, Pourghasemi H R and Zeinivand H 2014 Groundwater potential mapping at Kurdistan region of Iran using analytic hierarchy process and GIS; Arab. J. Geosci. 8(9) 7059-7071, https://doi. org/10.1007/s12517-014-1668-4.

Rahmati O, Pourghasemi H R and Melesse A M 2016 Application of GIS-based data driven random forest and 
maximum entropy models for groundwater potential mapping: A case study at Mehran region, Iran; Catena 137 360-372, https://doi.org/10.1016/j.catena.2015.10.010.

Shahid S, Nath S K and Kamal A S 2014 GIS integration of remote sensing and topographic data using fuzzy logic for ground water assessment in Midnapur district, India; Geocarto Int. 17 69-74.

Singh S K, Srivastava K, Gupta M, Thakur K and Mukherjee S 2014 Appraisal of land use/land cover of mangrove forest ecosystem using support vector machine; Environ. Earth Sci. 71 2245-2255.

Solomatine D, See L M and Abrahart R J 2008 Datadriven modelling: Concepts, approaches and experiences; In: Practical Hydroinformatics (eds) Abrahart R J et al., Water Science and Technology Library 68, SpringerVerlag, Berlin, Heidelberg, 68 17-30.

Corresponding editor: Prashant K SRIVAstava
Srivastava P K, Singh S K, Gupta M, Thakur J K and Mukherjee S 2013 Modeling impact of land use change trajectories on groundwater quality using remote sensing and GIS; Environ. Eng. Manag. J. 12 23432355.

Todd D K and Mays L W 2005 Groundwater hydrology; 3rd edn, Wiley, NJ, 636p.

van Westen C J, Rengers N, Terlien M T J and Soeters R 1997 Prediction of the occurrence of slope instability phenomena through GIS-based hazard zonation; Geol. Rundsch. 86 404-414.

Yesilnacar E K 2005 The application of computational intelligence to landslide susceptibility mapping in Turkey, Ph.D. Thesis, Department of Geomatics, University of Melbourne, 423p. 